\title{
Author Correction: Nuclear
}

\section{localization of Beclin 1 promotes radiation-induced DNA damage repair independent of autophagy}

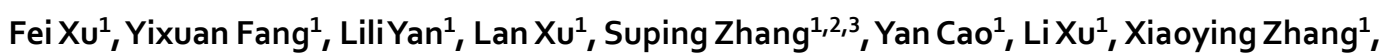
Jialing Xie ${ }^{1}$, Gaoyue Jiang ${ }^{1}$, Chaorong Ge ${ }^{1}$, Ni An ${ }^{1}$, Daohong $\mathrm{Zhou}^{3}$, $\mathrm{NaYuan}^{1,2}$ \& Jianrong Wang ${ }^{1,2}$

Correction to: Scientific Reports https://doi.org/10.1038/srep45385, published online 27 March 2017

This Article contains errors. In Figure 2C, the representative comet image for Beclin ${ }^{-1-}$ IR group is incorrect. The correct Figure 2C appears below as Figure 1.

In Figure 5B, the image flow cytometry is incorrect. The correct Figure 5B appears below as Figure 2.

In the legend of Supplementary Figure S1,

"GAPDH served as an internal control for cytoplasmic protein loading in (C)"

should read:

" $\beta$-actin served as an internal control for cytoplasmic protein loading in (C)"

In the legend of Supplementary Figure S3,

“(B) Immunoblotting analysis of the indicated wild-type cells and the various beclin 1 targeted Hela cell clones. GAPDH was used as an internal control in this and other figures”.

should read:

"(C) Immunoblotting analysis of the indicated wild-type cells and the various beclin1 targeted Hela cell clones. GAPDH was used as an internal control in this and other figures".

In Supplementary Figure S5B, the representative image for beclin $1^{-1-}$ Beclin 1 IR-3h group is incorrect. The correct Supplementary Figure S5B appears below as Figure 3.

Finally, in Supplementary Figure S7A, the statistical comparison of the histogram between $\operatorname{atg} 7^{-1-}$ Vector and atg $7^{-l-}$ Beclin1 should be '**', not 'ns'”. The correct Supplementary Figure S7A appears below as Figure 4.

\footnotetext{
${ }^{1}$ Hematology Center of Cyrus Tang Medical Institute, Collaborative Innovation Center of Hematology, Soochow University School of Medicine, Suzhou, 215123, China. ${ }^{2}$ Jiangsu Institute of Hematology, Jiangsu Key Laboratory for Stem Cell Research, The First Affiliated Hospital, Soochow University School of Medicine, Suzhou, 215123, China. ${ }^{3}$ Division of Radiation Health, Department of Pharmaceutical Sciences, University of Arkansas Medical Sciences, Little Rock, Arkansas, 72205, USA. Correspondence and requests for materials should be addressed to N.Y. (email: nyuan@suda.edu.cn) or J.W. (email: jrwang@suda.edu.cn)
} 
C
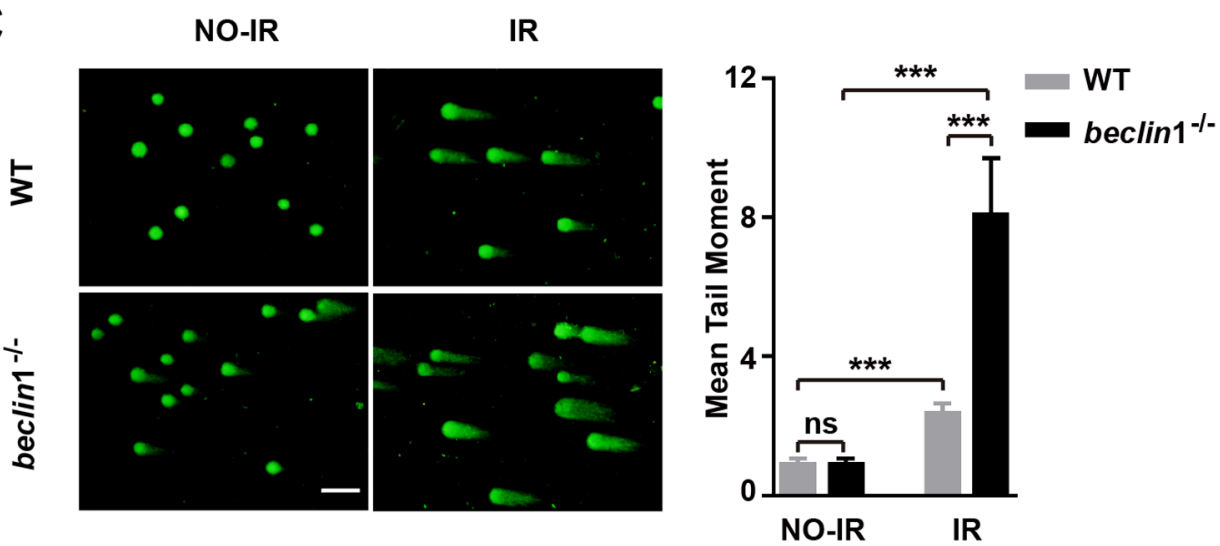

Figure 1.

B

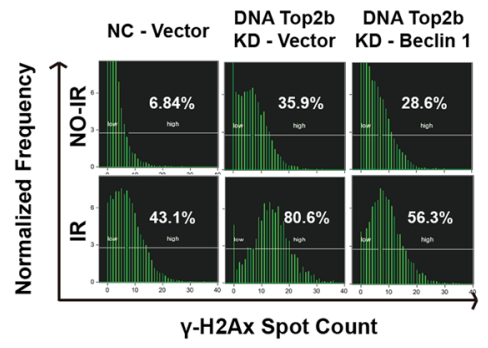

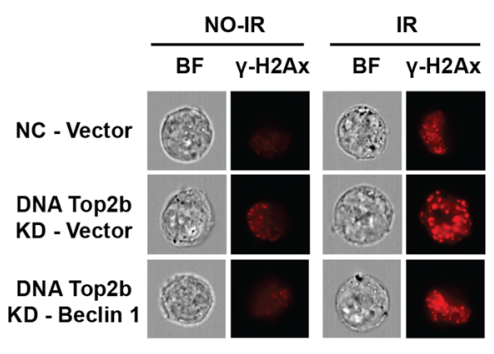

KD - Beclin

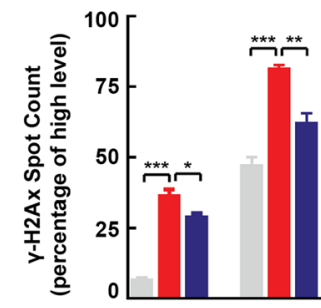

Top2b siRNA - + + - + +

Flag-Beclin $1 \frac{--+}{\text { NO-IR }} \frac{-\cdot+}{\mathrm{IR}}$

Figure 2. .

B beclin1 $1^{-/-}$Vector beclin1 ${ }^{-/-}$- Beclin 1

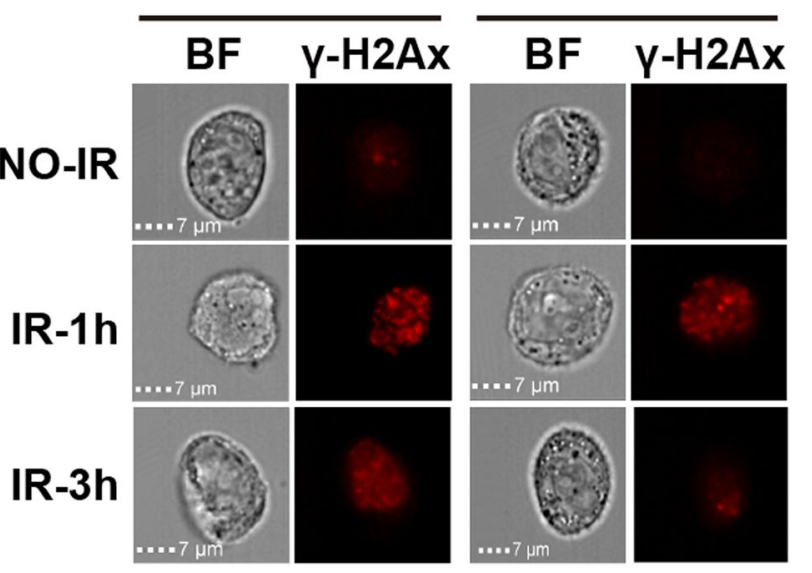

Figure 3. 


\section{A}
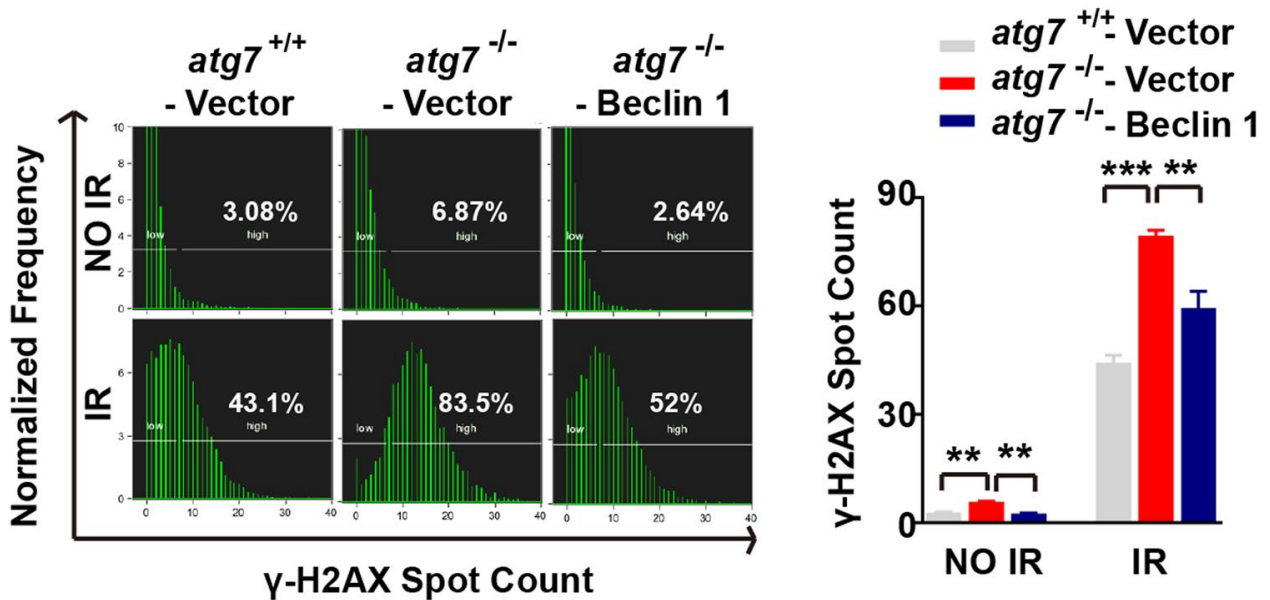

Figure 4. .

(1) Open Access This article is licensed under a Creative Commons Attribution 4.0 International License, which permits use, sharing, adaptation, distribution and reproduction in any medium or format, as long as you give appropriate credit to the original author(s) and the source, provide a link to the Creative Commons license, and indicate if changes were made. The images or other third party material in this article are included in the article's Creative Commons license, unless indicated otherwise in a credit line to the material. If material is not included in the article's Creative Commons license and your intended use is not permitted by statutory regulation or exceeds the permitted use, you will need to obtain permission directly from the copyright holder. To view a copy of this license, visit http://creativecommons.org/licenses/by/4.0/.

(c) The Author(s) 2019 